\title{
Bushen-Yizhi formula ameliorates cognition deficits and attenuates oxidative stress-related neuronal apoptosis in scopolamine-induced senescence in mice
}

\author{
XUE-QIN HOU $^{1 *}$, DIAN-WEI WU ${ }^{2 *}$, CHUN-XIA ZHANG $^{1}$, RONG YAN $^{1}$, CONG YANG $^{1}$, \\ CUI-PING RONG ${ }^{1}$, LEI ZHANG ${ }^{1}$, XIANG CHANG ${ }^{1}$, RU-YU SU ${ }^{1}$, SHI-JIE ZHANG ${ }^{1}$, WEN-QING HE ${ }^{1}$, \\ ZHAO QU ${ }^{1}$, SHI LI ${ }^{1}$, ZI-REN SU ${ }^{3}$, YUN-BO CHEN ${ }^{1}$, QI WANG ${ }^{1}$ and SHU-HUAN FANG ${ }^{1}$ \\ ${ }^{1}$ Institute of Clinical Pharmacology, Guangzhou University of Chinese Medicine, Guangzhou, Guangdong 510405;
${ }^{2}$ Shantou Hospital of Traditional Chinese Medicine, Guangzhou, Guangdong 515031; ${ }^{3}$ School of Chinese Materia Medica,
Guangzhou University of Chinese Medicine, Guangzhou, Guangdong 510006, P.R. China
}

Received February 11, 2014; Accepted May 20, 2014

DOI: $10.3892 / \mathrm{ijmm} .2014 .1801$

\begin{abstract}
Bushen-Yizhi formula (BSYZ), a traditional Chinese medicine formula consisting of six herbs has been reported to possess a neuroprotective effect. The present study aimed to investigate the effects of BSYZ on learning and memory abilities, as well as oxidative stress and neuronal apoptosis in the hippocampus of scopolamine (SCOP)-induced senescence in mice, in order to reveal whether BSYZ is a potential therapeutic agent for Alzheimer's disease (AD). A high-performance liquid chromatography (HPLC) fingerprint was applied to provide a chemical profile of BSYZ. Extracts of BSYZ were orally administered to mice with SCOP-induced memory impairment for two weeks. The learning and memory abilities were determined by the Morris water maze test. The oxidant stress-related indices, such as activity of superoxide dismutase (SOD) and levels of glutathione (GSH) and malondialdehyde (MDA) were examined in hippocampus of SCOP-treated mice. The cell death ratio was assessed by TUNEL staining, while apoptotic-related proteins including Bcl-2 and Bax were determined by immunofluorescent staining and western blot analysis. Caspase- 3 was determined by western blot analysis. Consequently, a chromatographic condition, which was conducted at $35^{\circ} \mathrm{C}$ with a flow rate of $0.8 \mathrm{ml} / \mathrm{min}$ on the Gemini C18 column with mobile phase of acetonitrile
\end{abstract}

Correspondence to: Professor Shu-Huan Fang or Professor Qi Wang, Institute of Clinical Pharmacology, Guangzhou University of Chinese Medicine, Guangzhou, Guangdong 510405, P.R. China

E-mail: fshkm@126.com

E-mail:wqitcm@qq.com

*Contributed equally

Key words: Alzheimer's disease, scopolamine, Bushen-Yizhi formula, antioxidant, antiapoptosis, neuroprotection and water-phosphoric acid (100:0.1, v/v), was established to yield common fingerprint chromatography under $203 \mathrm{~nm}$ with a similarity index of 0.986 within 10 batches of BSYZ samples. $\mathrm{BSYZ}$ at a dose of $2.92 \mathrm{~g} / \mathrm{kg}$ significantly improved the cognitive ability, restored the abnormal activity of SOD and increased the levels of MDA and GSH induced by SCOP. Moreover, the neural apoptosis in the hippocampus of SCOP-treated mice was reversed by BSYZ by regulating the expression of Bcl-2, Bax and caspase-3. The results demonstrated that BSYZ had neuroprotective effects in SCOP-induced senescence in mice by ameliorating oxidative stress and neuronal apoptosis in the brain, supporting its potential in AD treatment.

\section{Introduction}

Alzheimer's disease (AD) is a progressive neurodegenerative disease accompanied by neuronal loss in the brain and cognitive impairments. The exact pathogenesis is still unknown although several theories have been revealed and accepted. Cholinergic system dysfunction was one of the most important pathogenesis of AD (1-3). Acetylcholinesterase inhibitor, a target drug of the cholinergic system, has been used to treat mild to moderate $\mathrm{AD}$ in clinical trials in recent years $(4,5)$. Scopolamine (SCOP), an anticholinergic agent, has been reported to induce some features that are similar to $\mathrm{AD}$, such as affective disorder and memory impairment, and was widely used to induce the cognitive impairment model for investigation of AD (6-8). Studies have shown that it induced oxidative stress in SCOP-treated animals (9). Oxidative stress, another important pathogenesis of AD (10), was associated with neuronal loss or apoptosis $(11,12)$. Since the pathogenesis is complicated, the target of therapy is diverse. Multi-targeted drugs play an increasingly important role in the treatment of AD (13). Chinese medicine recipes, comprising multi-components, serve as a potential multi-targeted drug. Certain compound recipes (14-16) exert beneficial effects on cognitive ability in memory-impaired animal models and are crucial in the clinical therapy of AD patients. In the traditional Chinese medicine theory, 
deficiency of kidney was considered to be the root cause of AD. Thus, the therapy of reinforcing kidney was widely used in the clinic by using 'kidney-reinforcing' herbs or prescription (17) which were reported to possess anti-AD effects. Moreover, different herbs had different effects on brain functions, such as antioxidant, anti-apoptotic and anti-acetylcholinesterase activities $(18,19)$. The Bushen-Yizhi formula (BSYZ) is a traditional Chinese medicine compound recipe consisting of common Cnidium fruit (CCF), tree peony bark (TPB), ginseng root (GR), Radix Polygoni Multiflori Preparata (RPMP), barbary wolfberry fruit (BWF) and Fructus Ligustri Lucidi (FLL). In traditional Chinese medicine theory, BSYZ had an effect of 'kidney-reinforcing' and 'brain nourishing' based on the single effect of those six herbs as well as the effect of compatibility of traditional Chinese medicine, which was considered to play a more important role in treatment of disease. Previous studies have shown that the medicine-containing serum of BSYZ exerted effects of enhancing choline acetyltransferase (ChAT) activity and neurotransmitter release in a cell model of A $\beta 25$-35-induced $\operatorname{AD}(20,21)$. However, additional evidence is required to reveal the potential therapeutic effects of BSYZ in AD. In this study, we investigated the effects of BSYZ extraction on improving cognitive disorder in SCOP-induced senescence in mice by Morris water maze test, a common method for assessing learning and memory abilities of animals. Additionally, the effects of BSYZ on oxidative stress-related apoptosis were investigated to illuminate the underlying mechanisms.

\section{Materials and methods}

Materials. Ginsenoside Rb1, Ginsenoside Rg1, Osthole, Imperatorin, Paeoniflorin, Paeonolum, Oleanic acid and $2,3,5,4$ '-tetrahydroxystilbene-2-O- $\beta$-D-glucoside were purchased from the National Institutes for Food and Drug Control (Beijing, China). Acetonitrile [high performance liquid chromatography (HPLC) grade] was bought from Honeywell International Inc. (Burdick \& Jackson, Muskegon, MI, USA). SCOP hydrobromide injection (Guangzhou Baiyun mountain Mingxing Pharmaceutical Co., Ltd., Guangzhou, China) was purchased from Guangzhou Pharmaceuticals Corporation (Guangzhou, China). Acricept (Henan Joyline \& Joysun Pharmaceutical Stock Co., Ltd., Zhengzhou, China) was dissolved in $0.9 \%$ physiological saline. Kits used for determination of superoxide dismutase (SOD), malondialdehyde (MDA) and glutathione (GSH) were purchased from the Nanjing Jiancheng Bioengineering Institute (Nanjing, China). Primary antibodies (Bcl-2, caspase- 3 and $\beta$-actin) were obtained from Cell Signaling Technology, Inc. (Beverly, MA, USA). Anti-Bax antibody was purchased from Santa Cruz Biotechnology, Inc. (Santa Cruz, CA, USA). Secondary antibodies (horseradish peroxidase-conjugated anti-rabbit IgG and anti-mouse $\operatorname{IgG}$ ) were purchased from Cell Signaling Technology, Inc. Other reagents were of AR grade.

Preparation of sample solution. BSYZ consisted of six medicinal plants (Table I). All the raw herbs were purchased from the Guangxi Yifang Chinese Herbal Medicine Department and identified by Professor Jiannan Chen, pharmacognosist of the School of Chinese Materia Medica, Guangzhou University of Chinese Medicine. All of these accorded with the standard described in the 2010 edition of China Pharmacopoeia. The contents of BSYZ or dried powder of single herb were weighed and subjected to an ultrasonic extraction with $60 \mathrm{ml}$ of $70 \%$ methanol for $30 \mathrm{~min}$. The extract solution was then filtered through a $0.45 \mu \mathrm{m}$ filter membrane prior to analysis.

HPLC analysis. The HPLC equipment was Dionex Summit HPLC system, equipped with a PDA-100 detector, a P680 pump, an ASI-100 automatic sampler, and a STH585 thermostatic column compartment. The chromatographic separation was carried out at $35^{\circ} \mathrm{C}$ with a flow rate of $0.8 \mathrm{ml} / \mathrm{min}$ on a Gemini-C18 110A $(150 \times 2.00 \mathrm{~mm}, 5 \mu \mathrm{m})$. The mobile phase was A (acetonitrile) and B (water-phosphoric acid, 100:0.1, v/v), and $10 \mu \mathrm{l}$ capacity per injection was used. The elution program was optimized and conducted as follows: 0-23 min, linear gradient 5-19\% A; 23-33 min, linear gradient 19-22\% A; 33-48 min, linear gradient 22-32\% A; 48-60 min, linear gradient 32-75\% A; 60-61 min, linear gradient 75-80\% A; 61-66 min, linear gradient $80 \%$ A; 66-78 min, linear gradient $80-5 \% \mathrm{~A}$; and $78-80 \mathrm{~min}$, linear gradient $5 \% \mathrm{~A}$. Monitoring was performed at $203 \mathrm{~nm}$ with PDA detector. Data analysis was performed by a similarity evaluation system for chromatographic fingerprint of traditional Chinese medicine (Version 2004A, The Pharmacopoeia Commission of PRC, Beijing, China), which was recommended by the State Food and Drug Administration (SFDA) of China. The software was usually used to evaluate the similarities of different chromatograms and calculate the correlative coefficient of different patterns.

Animals and drug administration. Male Kunming mice (8-month-old, weighing 50-60 g) were purchased from the Experimental Animal Center of Sun Yat-Sen University (Guangzhou, China). Mice were maintained on standard laboratory conditions with food and water ad libitum for the duration of the study. The animal experiments were approved by the Animal Ethics Committee of Guangzhou University of Chinese Medicine. Mice were randomly divided into six groups $(\mathrm{n}=9)$ : the vehicle control group ( $0.9 \% \mathrm{NaCl}$ treatment), SCOP group (SCOP $2 \mathrm{mg} / \mathrm{kg}$ ), Aricept group ( $\mathrm{SCOP}+$ Aricept $3 \mathrm{mg} / \mathrm{kg}$ ), low dose BSYZ group (SCOP + BSYZ $1.46 \mathrm{~g} / \mathrm{kg}$ ), medium dose BSYZ group (SCOP + BSYZ $2.92 \mathrm{~g} / \mathrm{kg}$ ) and high dose BSYZ group (SCOP + BSYZ $5.84 \mathrm{~g} / \mathrm{kg}$ ). Mice were orally administered saline, Aricept or BSYZ, once per day for two weeks. In the vehicle control and SCOP groups, mice were treated similarly with corresponding volumes of saline. The mice, with the exception of the vehicle control group, were intraperitoneally administered SCOP 30 min prior to the Morris water maze test.

Morris water maze test. The Morris water maze test was similar to the method of Morris (22), with minor modifications (23). The equipment (Guangzhou Feidi Biology Technology Co., Ltd., Guangzhou, China) consisted of a black circular pool $(120 \mathrm{~cm}$ in diameter and $40 \mathrm{~cm}$ in height), filled to a depth of $30 \mathrm{~cm}$ with water $\left(22-26^{\circ} \mathrm{C}\right)$ and a non-toxic water-soluble black colored dye. The pool was divided into four equal quadrants and a black escape platform $(8 \mathrm{~cm}$ in 
Table I. Constituents of BSYZ.

\begin{tabular}{lc}
\hline Components & Ratio \\
\hline $\begin{array}{l}\text { She Chuang Zi } \\
\text { (Cnidium monnieri L. Cuss., fruit) }\end{array}$ & 3 \\
Ren Shen & 3 \\
(Panax ginseng C. A. Mey., rhizome) & 2 \\
$\begin{array}{l}\text { Zhi He Shou Wu } \\
\text { (Preparata of Polygonum multiflorum Thuna., radix) }\end{array}$ & \\
$\begin{array}{l}\text { Mu Dan Pi } \\
\text { (Paeonia suffruticosa Andr., cortex) }\end{array}$ & 2 \\
$\begin{array}{l}\text { Nv Zhen Zi } \\
\text { (Ligustrum lucidum Ait., fruit) }\end{array}$ & 2 \\
$\begin{array}{l}\text { Gou Qi } \\
\text { (Lycium barbarum L., fruit) }\end{array}$ & 2 \\
\hline
\end{tabular}

BSYZ, Bushen-Yizhi formula.

diameter, $1 \mathrm{~cm}$ below the water surface) was placed in the center of one of the pool quadrants. The learning and memory ability of mice was detected by the Morris water maze test in a dark room. Mice were given a place navigation test for five consecutive days. On each training day, there were four sequential training trials for each mouse from four different entry positions equally spaced around the perimeter of the pool. A trial began by placing the animal in the water facing the wall of the pool at one starting point and the escape latency was recorded at the end. If it failed to find the platform within $60 \mathrm{sec}$, the mouse was guided to the platform by the experimenter and allowed to stay there for $20 \mathrm{sec}$ and its escape latency was recorded as $60 \mathrm{sec}$. After four trials, the mouse was dried and returned to its cage at the end. On the sixth day, the probe test was performed in the absence of the platform with a cut-off time of $60 \mathrm{sec}$. The number of crossing through the original position of the platform and the time spent in the target quadrant were measured.

Biochemical analysis (assay of SOD activity, MDA and GSH level). After the Morris water maze test, six mice from each group were anesthetized and decapitated. Brains were removed carefully and dissected into hippocampus and cortex on an ice-cold plate. Tissues were rapidly stored at $-80^{\circ} \mathrm{C}$ until use. Parts of samples were used for biochemical analysis and western blot analysis.

For the biochemical analysis, the hippocampus was weighed and homogenized with ice-cold saline in a glass homogenizer to make $10 \%$ (weight/volume) tissue homogenate. Homogenate was centrifuged at $3,000 \mathrm{x}$ g for $10 \mathrm{~min}$ at $4^{\circ} \mathrm{C}$ and the supernatant was used to assay SOD activity, MDA and GSH contents by using the commercial kits according to the manufacturer's instructions. The absorbance was read at 550, 532 and $420 \mathrm{~nm}$, respectively, using Universal Microplate Spectrophotometer (Bio-Rad, Hercules, CA, USA). The levels of SOD activity, MDA and GSH contents were expressed as U/mg protein, $\mathrm{nmol} / \mathrm{mg}$ protein and $\mu \mathrm{g} / \mathrm{mg}$ protein, respectively.
Preparation of sections. Three mice from each group were anesthetized and decapitated. Brains were removed carefully and quickly fixed in $4 \%$ paraformaldehyde in $0.1 \mathrm{M}$ phosphate-buffered saline (PBS, $\mathrm{pH} 7.4$ ) for $24 \mathrm{~h}$, dehydrated with a graded series of ethanol, embedded in paraffin blocks and sliced at $4 \mu \mathrm{m}$ thickness.

TUNEL staining. TUNEL staining was performed using the In Situ Cell Death Detection kit (Roche Diagnostics GmbH, Mannheim, Germany), according to the manufacturer's instructions. Briefly, the sections were heated at $60^{\circ} \mathrm{C}$ for $1 \mathrm{~h}$, washed in xylene and rehydrated through a graded series of ethanol and double-distilled water. After treating sections with $0.1 \mathrm{M}$ citrate buffer ( $\mathrm{pH}$ 6.0) by microwave oven for 1 min and cooling them to room temperature, the sections were washed in PBS and incubated with $50 \mu 1$ TUNEL reaction mixture for $1 \mathrm{~h}$ at $37^{\circ} \mathrm{C}$ in the dark. Further incubation with $50 \mu 1$ converter-POD was performed at $37^{\circ} \mathrm{C}$ for $30 \mathrm{~min}$. The sections were then rinsed with PBS and stained with DAB substrate for $10 \mathrm{~min}$ at room temperature. Images were captured and analyzed at a magnification of x 200 by using a light microscope and LEICA QWin plus (Leica Microsystems, Wetzlar, Germany). Average TUNEL-positive cells of each animal were obtained from three adjacent sections.

Immunofluorescent staining of Bcl-2 and Bax proteins. Sections were dewaxed and rehydrated by conventional methods. After quenching endogenous peroxidase with $3 \%$ hydrogen peroxide for $10 \mathrm{~min}$ and blocking with normal goat serum for $10 \mathrm{~min}$ at $37^{\circ} \mathrm{C}$, sections were incubated with rabbit anti-Bax antibody (1:200) and mouse anti-Bcl-2 antibody (1:200) (both from Santa Cruz Biotechnology, Inc.) at $4^{\circ} \mathrm{C}$ overnight. After washing in PBS, the sections were incubated with FITC-conjugated anti-rabbit $\operatorname{IgG}$ (1:500) and Cy3 conjugated anti-mouse IgG (1:200) (both from Beijing Cowin Biotech Co., Ltd., Beijing, China) for $1 \mathrm{~h}$ at room temperature in the dark. Images were captured at a magnification of x200 for analysis. The mean fluorescence intensity (MFI) was measured, and expression levels of Bax and Bcl-2 were calculated as change of the percentage in MFI compared to the vehicle control mice.

Western blot analysis. For western blot analysis assay, the hippocampus was homogenized and lysed in ice-cold RIPA buffer (containing 1:100 PMSF, 1:100 inhibitor proteases and phosphatases cocktail) for $15 \mathrm{~min}$. The lysate was centrifuged at $12,000 \mathrm{x} \mathrm{g}$ for $15 \mathrm{~min}$ at $4^{\circ} \mathrm{C}$ and the supernatant was removed to a new $1.5 \mathrm{ml}$ centrifuge tube. The protein concentrations were detected according to the manufacturer's instructions of the BCA protein assay kit (Nanjing Biobox Biotech. Co., Ltd., Nanjing, China). Samples ( $40 \mu \mathrm{g}$ of protein) were subjected to SDS-PAGE analysis in $12 \%$ gel. The separated protein was then transferred to PVDF membranes. The membranes were blocked with $5 \%$ non-fat milk dissolved in Tris-buffered saline-Tween-20 (TBST) for $1 \mathrm{~h}$ at room temperature and subsequently incubated with rabbit anti-Bcl-2 (1:2,000, Cell Signaling Technology, Inc.), rabbit anti-Bax (1:2,000, Santa Cruz Biotechnology, Inc.), rabbit anti-caspase-3 $(1: 2,000)$ and mouse anti- $\beta$-actin $(1: 5,000)$ (both from Cell Signaling Technology, Inc.) overnight at $4^{\circ} \mathrm{C}$. The membranes were subsequently washed three times in TBST for 
Table II. Effects of BSYZ on SOD activity, and MDA and GSH content in the hippocampus of scopolamine-treated mice.

\begin{tabular}{lccc}
\hline Group & $\begin{array}{c}\text { SOD } \\
(U / m g \text { protein })\end{array}$ & $\begin{array}{c}\text { MDA } \\
(\text { nmol/mg protein })\end{array}$ & $\begin{array}{c}\text { GSH } \\
(\mu \mathrm{g} / \mathrm{mg} \text { protein })\end{array}$ \\
\hline Vehicle control & $45.22 \pm 1.61$ & $0.25 \pm 0.11$ & $5.68 \pm 1.14$ \\
SCOP & $28.60 \pm 4.42^{\mathrm{a}}$ & $0.47 \pm 0.14^{\mathrm{a}}$ & $2.81 \pm 0.52^{\mathrm{a}}$ \\
SCOP + Aricept (3 mg/kg day) & $39.89 \pm 7.02^{\mathrm{b}}$ & $0.30 \pm 0.14^{\mathrm{b}}$ & $4.34 \pm 0.96^{\mathrm{b}}$ \\
SCOP + BSYZ (1.46 g/kg day) & $34.68 \pm 6.24$ & $0.38 \pm 0.08$ & $3.40 \pm 0.45$ \\
SCOP + BSYZ (2.92 g/kg day) & $38.56 \pm 8.00^{\mathrm{b}}$ & $0.26 \pm 0.04^{\mathrm{c}}$ & $5.18 \pm 0.40^{\mathrm{c}}$ \\
SCOP + BSYZ (5.84 g/kg day) & $30.50 \pm 3.02$ & $0.35 \pm 0.07$ & $4.17 \pm 0.76^{\mathrm{b}}$ \\
\hline
\end{tabular}

BSYZ, Bushen-Yizhi formula; SOD, superoxide dismutase; MDA, malondialdehyde; GSH, glutathione. Data are shown as the mean \pm SE $(\mathrm{n}=4) .{ }^{\mathrm{a}} \mathrm{P}<0.01$ versus the vehicle control mice, ${ }^{\mathrm{b}} \mathrm{P}<0.05$ and ${ }^{\mathrm{c}} \mathrm{P}<0.01$ versus the scopolamine-treated mice.

10 min each time and then incubated with horseradish peroxidase-conjugated anti-rabbit or anti-mouse IgG antibody (diluted at 1:5,000) for $1 \mathrm{~h}$ at room temperature. After washing the membranes in TBST three times, immunopositive bands were visualized using a super-enhanced chemiluminescense western blot analysis-detection reagent (ECL; Applygen Technologies Inc, Beijing, China). The optical density (OD) of bands on X-ray film was determined. $\beta$-actin was used as internal control. Results were expressed as the percentage of OD values by using the Image $\mathrm{J} 2 \mathrm{x}$ software system.

Statistical analysis. Data were shown as the mean $\pm \mathrm{SE}$ and analyzed using the Statistical Package for Social Science (SPSS) 17.0 software. In the Morris water maze test, escape latency was analyzed using repeated measures analysis of variance (ANOVA). When the Mauchly's test was significant, the differences between pairs of means were assessed by the multivariate analysis together with the least significant difference (LSD) post-hoc test. Other data obtained from the Morris water maze, and biochemical, TUNEL and western blot analyses were analyzed using one-way ANOVA. Values of $\mathrm{P}<0.05$ were considered to be statistically significant.

\section{Results}

HPLC analysis of the main components in BSYZ. The proposed HPLC analytical method was applied to acquiring the fingerprint of different batches of BSYZ samples. HPLC fingerprint of BSYZ is shown in Figs. 1 and 2. The relative retention time (RRA) and relative peak area (RPA) of all common peaks, whose relative standard deviation (RSD) values were $\leq 3.7 \%$, were obtained with reference to this substance. The results indicated the good stability and reproducibility of the fingerprint analysis by HPLC. The similarity indices of 10 batches of BSYZ samples were calculated using a similarity evaluation system. The results demonstrated that the samples showed good correlation and shared a similar chromatographic pattern with the similarity indices at $>0.986$. By comparing the retention times and UV spectra of the reference standards, eight compounds (Paeoniflorin, 2,3,5,4'-tetrahydro xystilbene-2-O- $\beta$-D-glucoside, Paeonolum, Ginsenoside Rg1, Ginsenoside Rb1, Imperatorin, Osthole, and Oleanic acid) in BSYZ were identified.
Morris water maze test. The spatial learning and memory ability of mice was tested by the Morris water maze test. As shown in Fig. 3A, the escape latency declined progressively during the five training days. The SCOP-treated mice spent longer period of time in finding the platform than the vehicle control mice from the third to fifth days $(\mathrm{P}<0.05, \mathrm{P}<0.05$ and $\mathrm{P}<0.01$, respectively). These results revealed that the SCOP-treated mice had significant cognitive impairment. Moreover, Aricept (3 mg/kg)- and BSYZ (2.92 g/kg)-treated mice significantly shortened the escape latency compared with the SCOP-treated mice on the fifth day (both $\mathrm{P}<0.05$ ). In the spatial probe test, the time spent in the target quadrant and the crossing times of the platform location were showed as Fig. 3B and C. Compared with the vehicle control group, SCOP-treated mice spent less time $(\mathrm{P}<0.01)$ in the target quadrant and crossed to the platform fewer times $(\mathrm{P}<0.01)$. In the Aricept ( $3 \mathrm{mg} / \mathrm{kg}$ )- and BSYZ (2.92 and $5.84 \mathrm{~g} / \mathrm{kg}$ )-treated mice, the test revealed a significant increase both in time spent in the quadrant of the platform placed and crossing counts compared with the SCOP-treated mice $(\mathrm{P}<0.01, \mathrm{P}<0.05$ and $\mathrm{P}<0.01$, respectively). Fig. 3D showed the swim tracks of mice in the fourth trial of the second and fifth days in the place navigation test. Mice tended to swim in circles around the wall of the pool on the second day. The mice gradually changed this search strategy within five training days. On the fifth day, SCOP-treated mice took a longer period of time and complex swimming tracks were noted, while the vehicle control mice swam in the direction of the platform. Aricept- and BSYZ-treated mice performed similar tracks to the vehicle control mice.

Effect of BSYZ on the SOD activity and MDA, GSH levels. The antioxidant effects of BSYZ in SCOP-treated mice are shown in Table II. SCOP treatment induced SOD activity decrease of $36.75 \%$ in the hippocampus. However, Aricept and BSYZ $(2.92 \mathrm{~g} / \mathrm{kg})$ treatment resulted in a significant elevation of enzyme activity in SCOP-treated mice, by increases of 39.37 and $34.82 \%$, respectively. The MDA level in the hippocampus of SCOP-treated mice induced an increase of $88 \%$ more than the vehicle control group $(\mathrm{P}<0.01)$. This increase was reversed by treatment with Aricept and BSYZ $(2.92 \mathrm{~g} / \mathrm{kg})$, with a percentage of 36.17 and $44.68 \%$, respectively. The GSH content significantly decreased in the hippocampus 
A 2,3,5,4'-tetrahydroxystilbene-2-O- $\beta$-D-glucoside
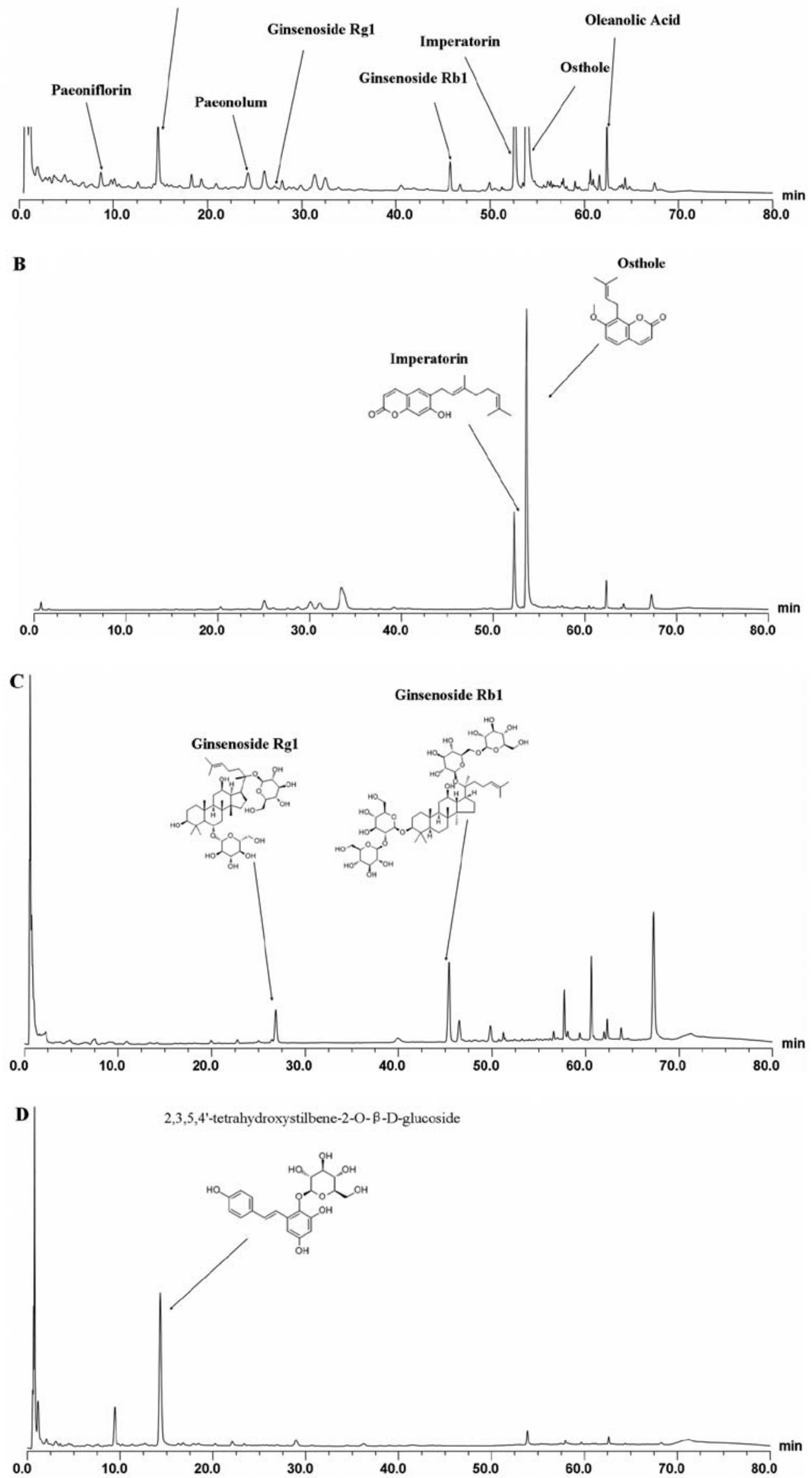

Figure 1. High-performance liquid chromatography (HPLC) pattern of Bushen-Yizhi formula (BSYZ) and single herbal extracts. (A) Structures of the constituents identified from BSYZ, (B) She Chuang Zi (Cnidium monnieri L. Cuss., fruit), (C) Ren Shen (Panax ginseng C. A. Mey., rhizome), (D) Zhi He Shou Wu (Preparata of Polygonum multiflorum Thuna., radix). 


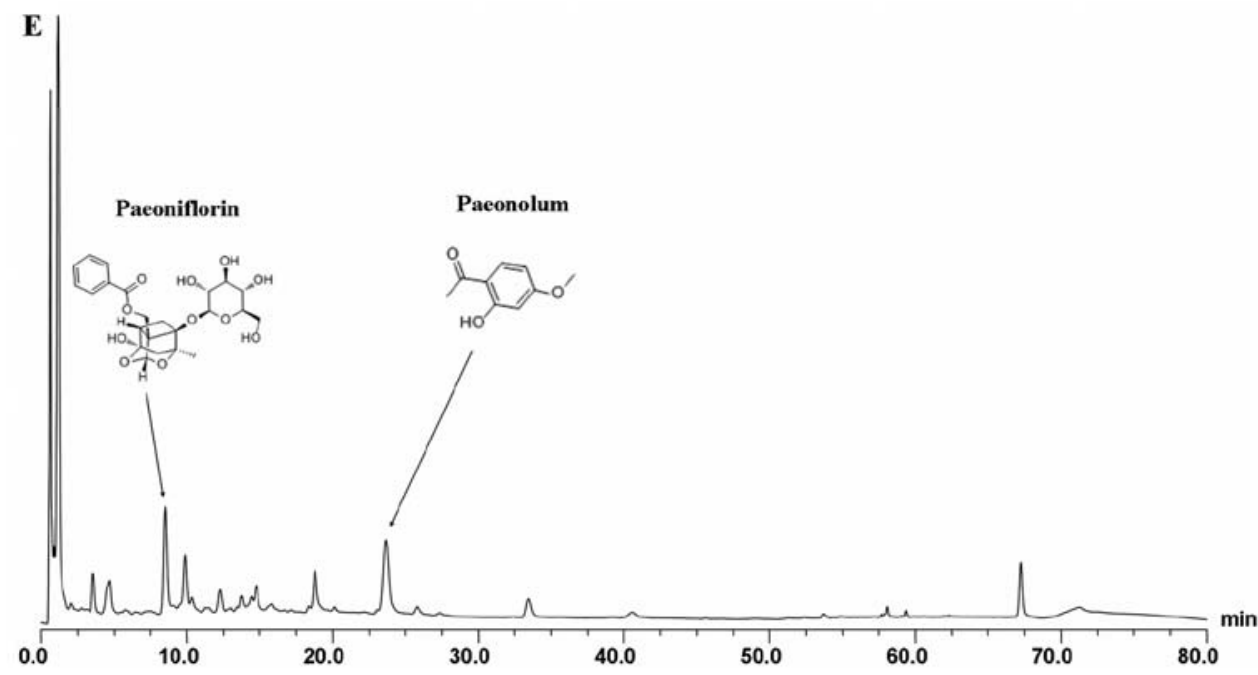

F
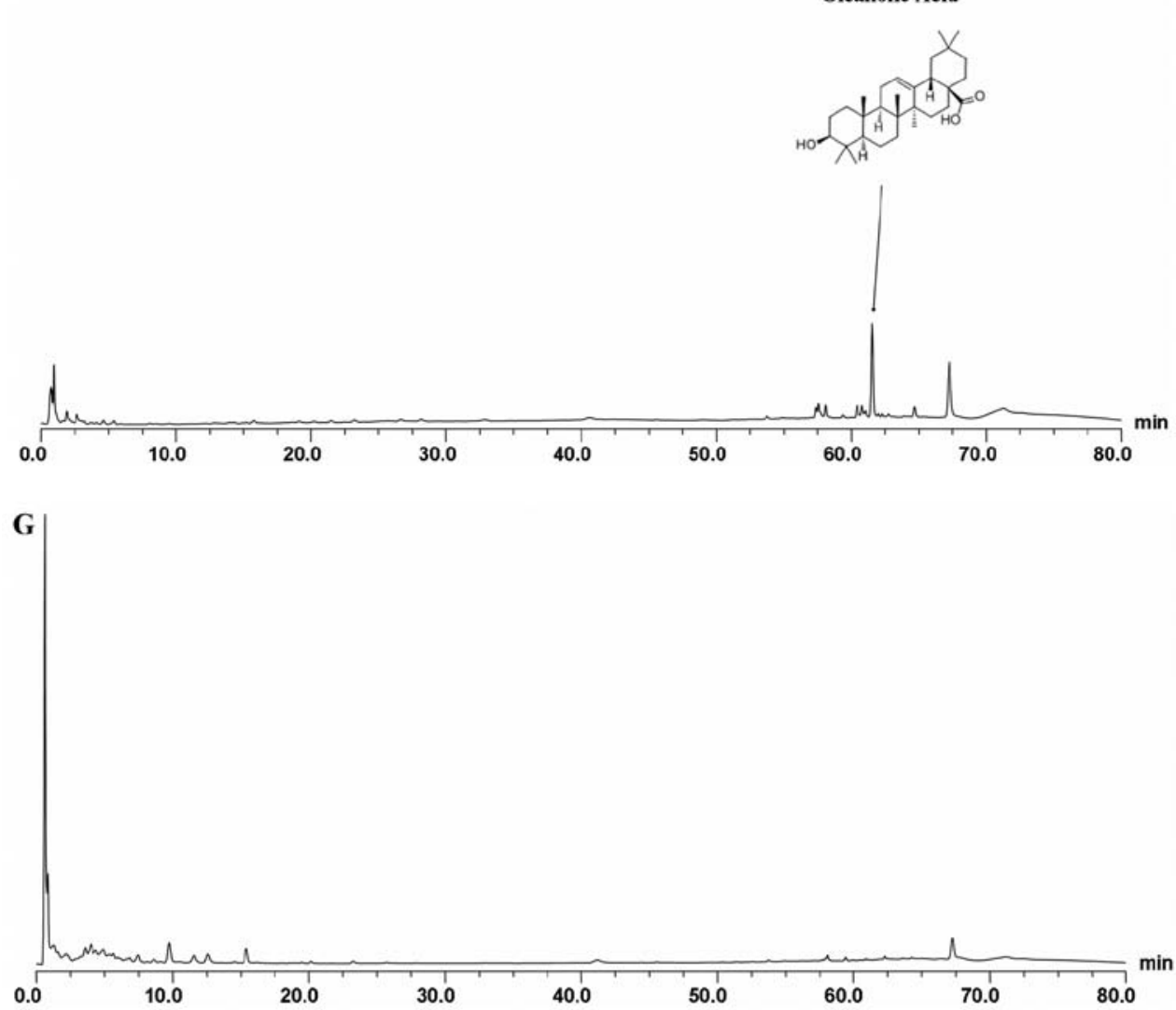

Figure 1. Continued.(E) Mu Dan Pi (Paeonia suffruticosa Andr., cortex), (F) Nv Zhen Zi (Ligustrum lucidum Ait., fruit), (G) Gou Qi (Lycium barbarum L., fruit).

of SCOP-treated mice compared with the vehicle control mice $(\mathrm{P}<0.01)$. Aricept and BSYZ $(2.92$ and $5.84 \mathrm{~g} / \mathrm{kg})$ treatment induced increases of the GSH level in the hippocampus of $1.54-$ - 1.84-, and 1.48-fold, respectively, compared with the SCOP-treated mice.

Effect of BSYZ on neuronal apoptosis in the hippocampus. Representative images of the TUNEL staining in hippocampus are shown in Fig. 4. TUNEL-positive cells were stained a deep brown in the hippocampus. Cell counting of the neuronal apoptosis in the hippocampus of SCOP-treated mice $(18.18 \pm 1.94 \%, \mathrm{P}<0.01)$ was prominently more than in the vehicle control mice (13.82 $\pm 1.78 \%)$. Aricept and BSYZ (2.92 and $5.84 \mathrm{~g} / \mathrm{kg}$ ) treatments markedly attenuated neuronal apoptosis in SCOP-treated mice $(15.24 \pm 0.47 \%, \mathrm{P}<0.01$; $14.11 \pm 0.26 \%, \mathrm{P}<0.01$; and $15.48 \pm 0.64 \%, \mathrm{P}<0.05$, respectively). These results indicated that BSYZ attenuated SCOP-induced apoptotic cell death in the hippocampus.

Effect of BSYZ on the expression of Bax and Bcl-2 proteins by immunofluorescent staining. The expression of Bax and Bcl-2 in the hippocampus of SCOP-treated mice was analyzed by immunofluorescent staining (Fig. 5A). As shown in Fig. 5B and C, the MFI of Bax in the hippocampus of SCOP-treated mice was 


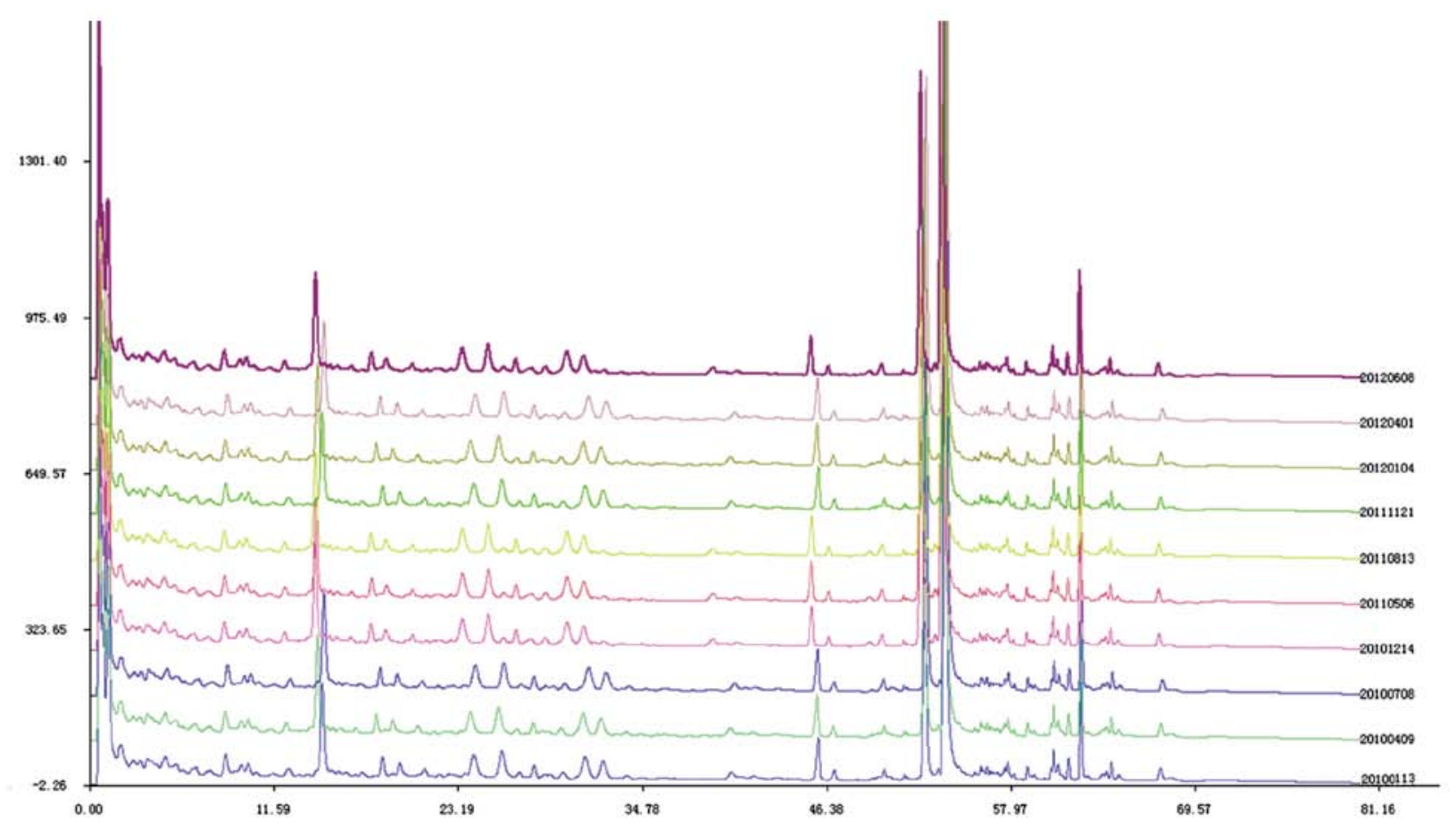

Figure 2. The chromatogram of 10 batches of Bushen-Yizhi formula (BSYZ) for similarity evaluation.

higher than the vehicle control group $(165.40 \pm 9.20 \%$ of control, $\mathrm{P}<0.01)$, while MFI for Bcl-2 was lower $(56.73 \pm 6.57 \%$ of control, $\mathrm{P}<0.01)$. Following treatment with BSYZ at a dose of $2.92 \mathrm{~g} / \mathrm{kg}$, MFI of Bax was markedly reduced $(136.72 \pm 8.26 \%$ of control, $\mathrm{P}<0.01)$, while Bcl-2 was significantly elevated $(73.59 \pm 4.49 \%$ of control, $\mathrm{P}<0.01)$. Treatment with Aricept showed a similar effect with BSYZ.

Effect of BSYZ on the expression of Bax, Bcl-2 and caspase-3 proteins by western blot analysis. The expression of Bax, Bcl-2 and caspase-3 proteins in the hippocampus of SCOP-treated mice was analyzed by western blot analysis. As shown in Fig. 6, the mean OD of Bcl-2 was lower in the SCOP-treated mice than the vehicle control group $(\mathrm{P}<0.01)$, while the mean optical densities of Bax and caspase-3 were higher than the vehicle control group $(\mathrm{P}<0.01)$. Following treatment with BSYZ at dose of $2.92 \mathrm{~g} / \mathrm{kg}$, the mean OD of Bcl-2 was significantly elevated $(\mathrm{P}<0.01)$, and the mean densities of Bax and caspase-3 were markedly reduced $(\mathrm{P}<0.01)$. The same effect was observed in the Aricept treatment group. In addition, BSYZ treatment at a dose of $1.46 \mathrm{~g} / \mathrm{kg}$ showed a downregulated effect on the expression of Bax and caspase-3 proteins $(\mathrm{P}<0.05)$.

\section{Discussion}

The gradual decline of learning and memory is a typical symptom of AD. Findings of previous studies have shown that a similar symptom was induced by SCOP (24), which is known as a cholinergic receptor antagonist. SCOP-treated animals have been widely used to estimate memory impairment and screening of potential cognition-enhancing agents. Oxidative stress and apoptosis changes, which are considered to be two important factors of pathogenesis of $\mathrm{AD}$, occur in this model $(6,25,26)$. In this study, we evaluated the effects of BSYZ on SCOP-induced memory impairments in mice by using Morris water maze test, biochemical assessments of oxidative stress indices and expression of apoptosis related proteins.

The Morris water maze test is widely used to evaluate the spatial learning and memory ability of animals $(6,9,27)$. In this study, it was shown that SCOP treatment prolonged the escape latency, shortened the time spent in the target quadrant and reduced the crossing times of the platform location compared with the control group. This indicates that the animals had a cognitive dysfunction. Moderate to high dose of BSYZ treatment showed a reverse effect similar to Aricept (also known as Donepezil) which is an acetylcholinesterase inhibitor and was approved to be used to treat mild and moderate dementia patients by the US Food and Drug Administration (FDA) in 1996. It has been widely used in studies of AD (28-30) and has shown antioxidant and anti-apoptotic activities (31).

Concerning oxidative stress, there was an imbalance of antioxidant systems, such as a decrease of SOD activity and GSH level, and an increase in the MDA level. In this study, the assessments of oxidative stress indices showed that SCOP-treated mice possessed a decreased SOD activity and GSH levels as compared to the control mice, while MDA levels were elevated. However, Aricept and BSYZ treatment increased SOD activity and the GSH level while reducing the MDA level. These results indicate that BSYZ may have potent antioxidant activity by exerting a protective effect against oxidative damage induced by SCOP.

Apoptosis, another important pathogenesis of AD, has been reported to be associated with the mechanism of central 

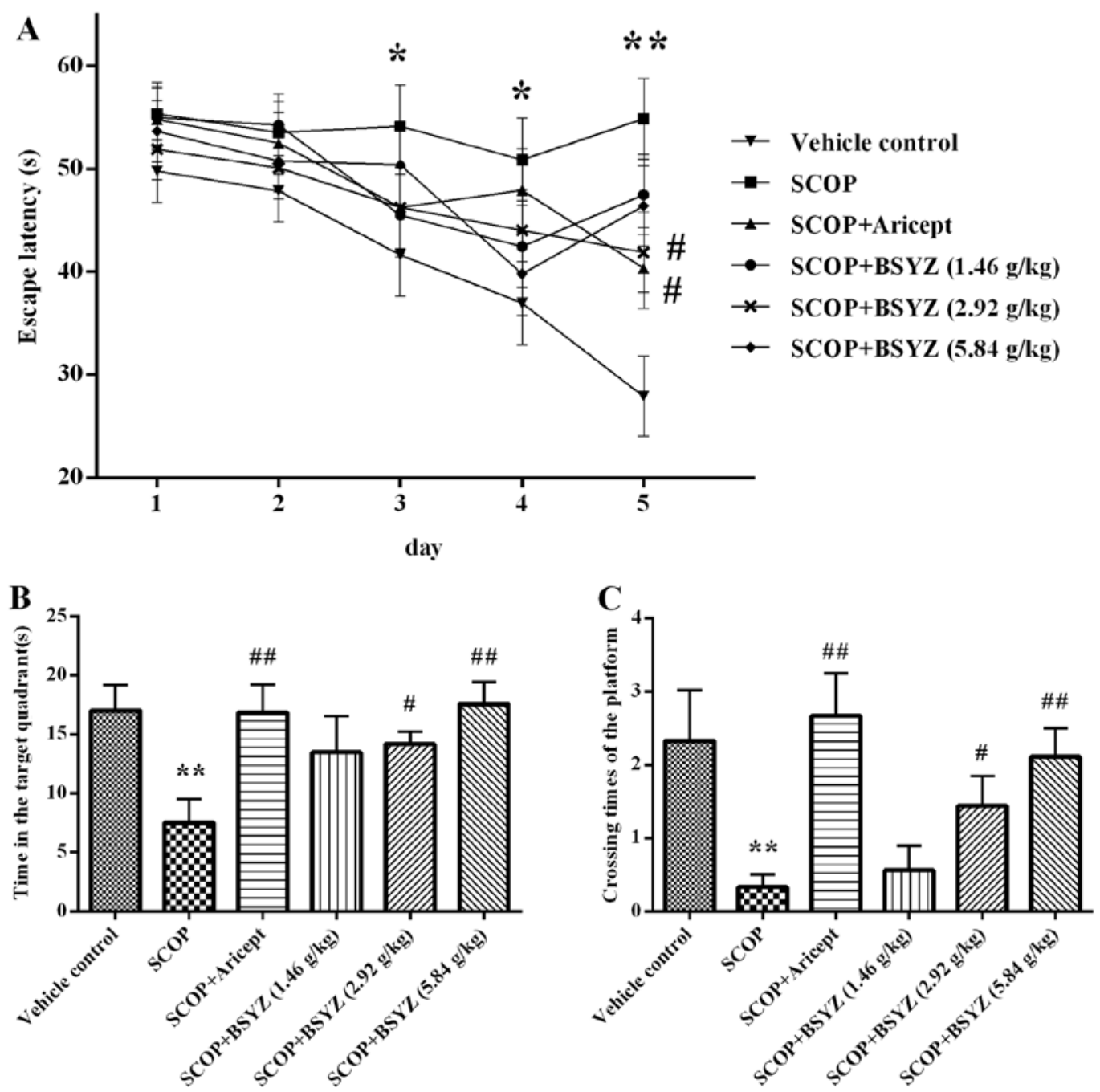

D
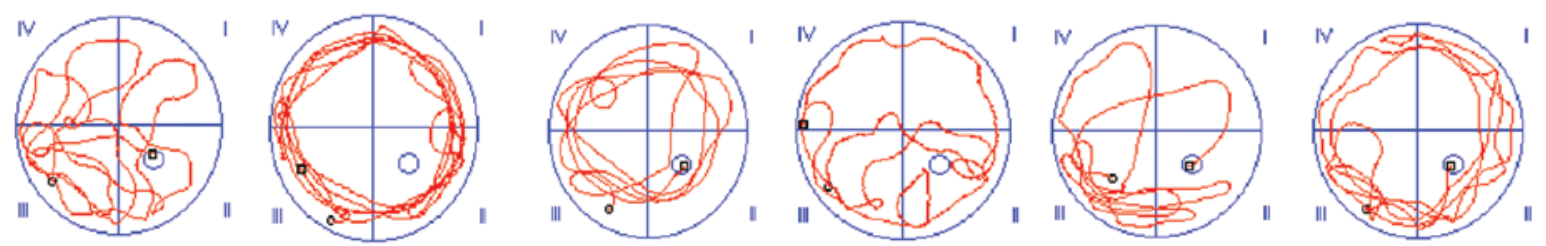

The fifth day

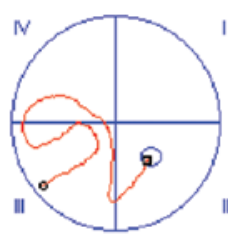

a

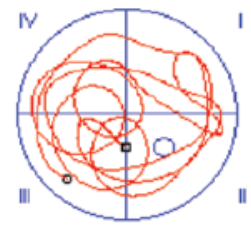

b

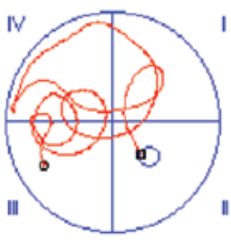

c

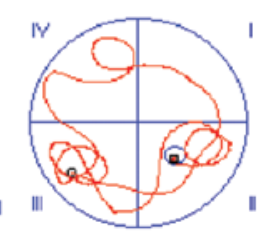

d

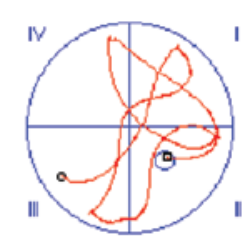

e

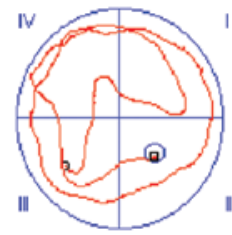

Figure 3. The Morris water maze test of mice. (A) Escape latencies in the water maze during five consecutive days test. (B) Time spent in the quadrant of platform placed within $60 \mathrm{sec}$. (C) Crossing times of the platform location. (D) Represent tracks of mice in the fourth trial on the second and fifth days; a, Vehicle control; b, SCOP; c, SCOP + Aricept; d, SCOP + Bushen-Yizhi formula (BSYZ) (1.46 g/kg); e, SCOP + BSYZ (2.92 g/kg); f, SCOP + BSYZ (5.84 g/ $\mathrm{kg}$ ) group. Data are shown as the mean $\pm \mathrm{SE}$. ${ }^{*} \mathrm{P}<0.05$ and ${ }^{* *} \mathrm{P}<0.01$ versus the vehicle control mice. ${ }^{\#} \mathrm{P}<0.05$ and ${ }^{\# \#} \mathrm{P}<0.01$ versus the $\mathrm{SCOP}$-treated mice.

cholinergic system dysfunction and oxidative stress. In the present study, we found that SCOP markedly increased neuronal apoptosis in the hippocampus by TUNEL staining. BSYZ and Aricept treatment improved this brain damage. 

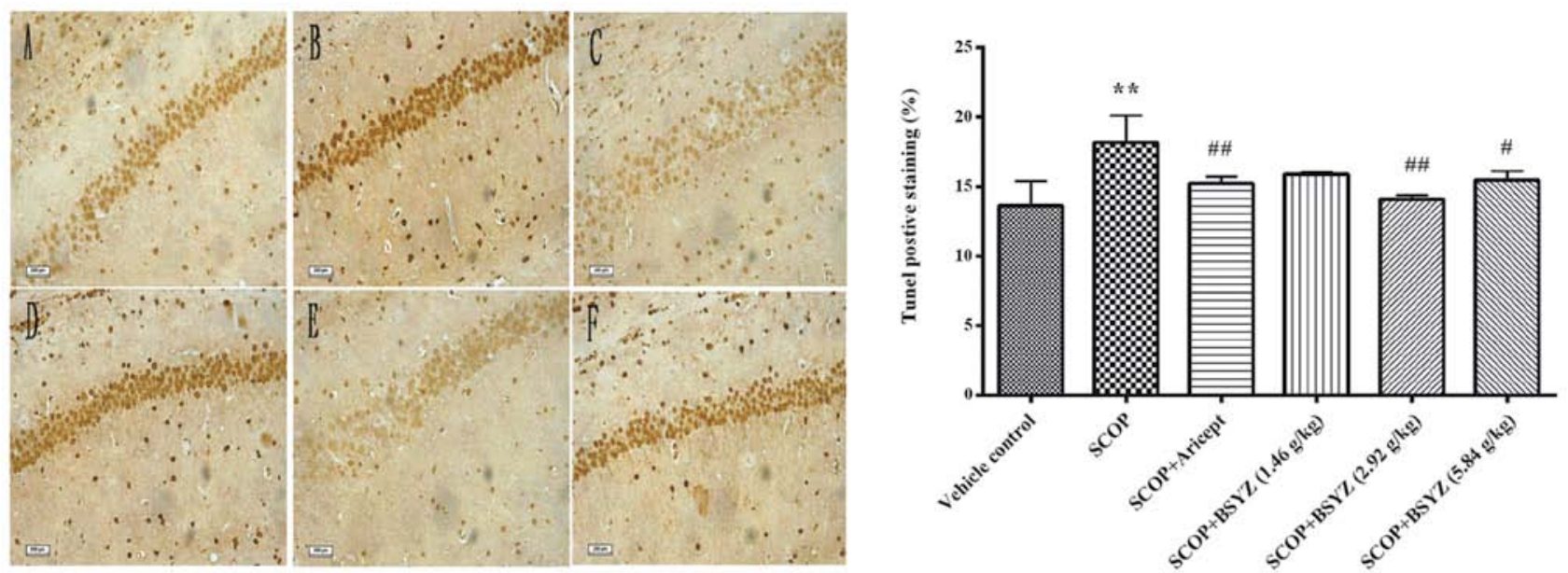

Figure 4. TUNEL staining in the hippocampus of scopolamine (SCOP)-treated mice. (A) Vehicle control; (B) SCOP; (C) SCOP + Aricept; (D) SCOP + Bushen-Yizhi formula (BSYZ) (1.46 g/kg); (E) SCOP + BSYZ (2.92 g/kg); (F) SCOP + BSYZ (5.84 g/kg); scale bar, $200 \mu \mathrm{m}$; original magnification, $\mathrm{x} 200$. Ratio of TUNEL-positive neurons is shown as the mean $\pm \mathrm{SE}(\mathrm{n}=3) .{ }^{* *} \mathrm{P}<0.01$ versus the vehicle control mice. ${ }^{\#} \mathrm{P}<0.05$ and ${ }^{\# \#} \mathrm{P}<0.01$ versus the SCOP-treated mice.

A
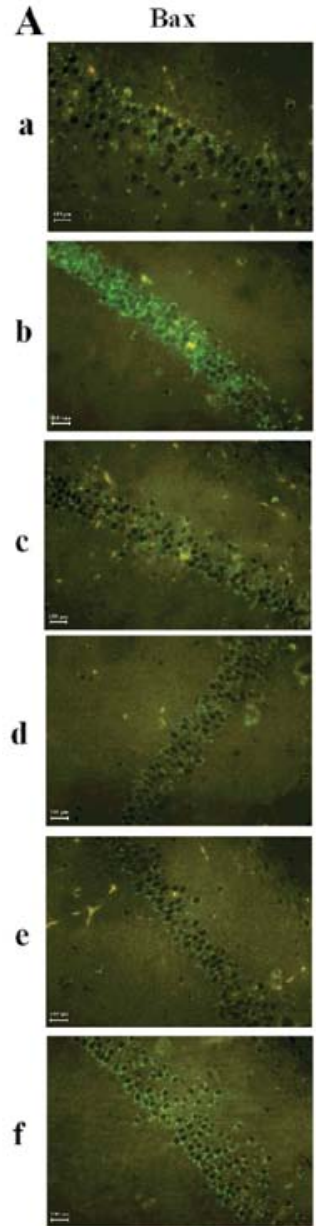

Bcl-2
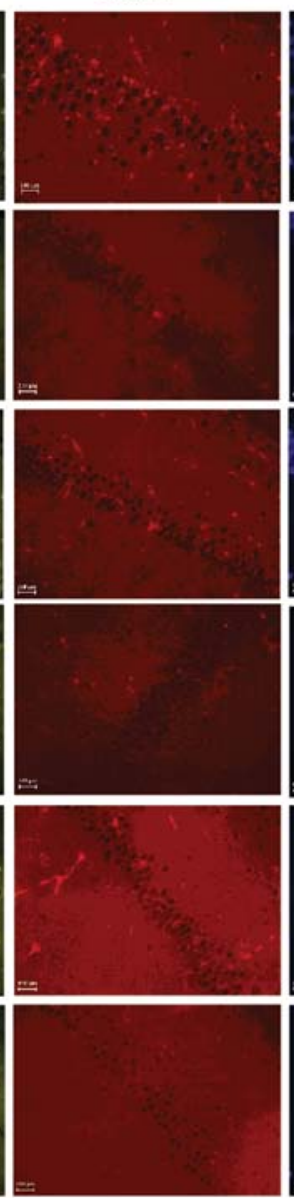
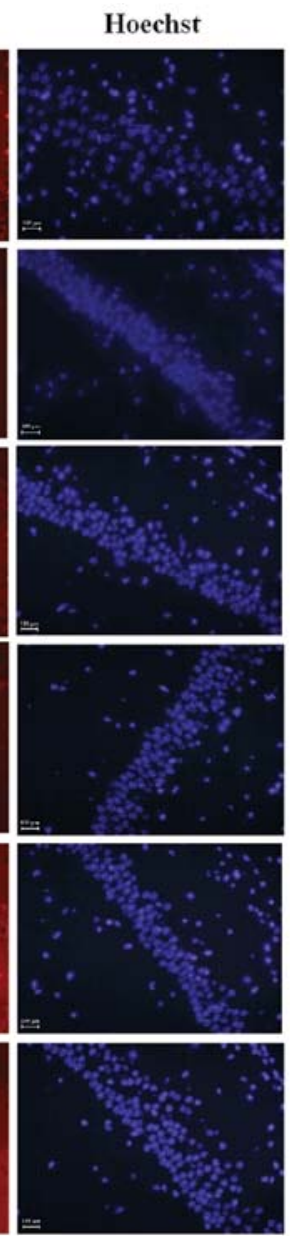

B

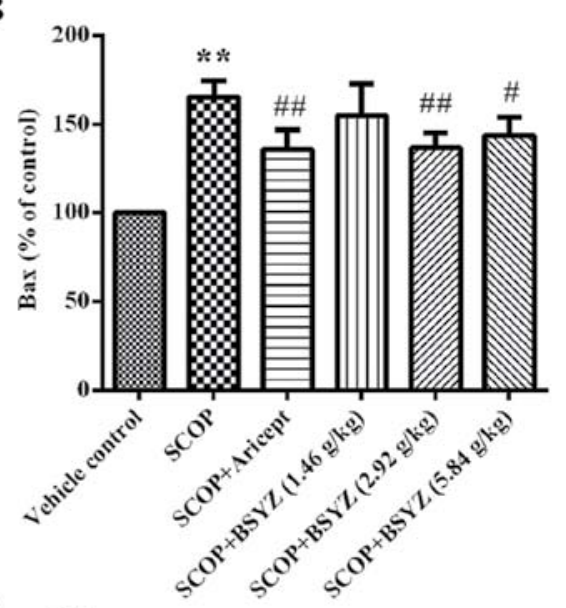

C

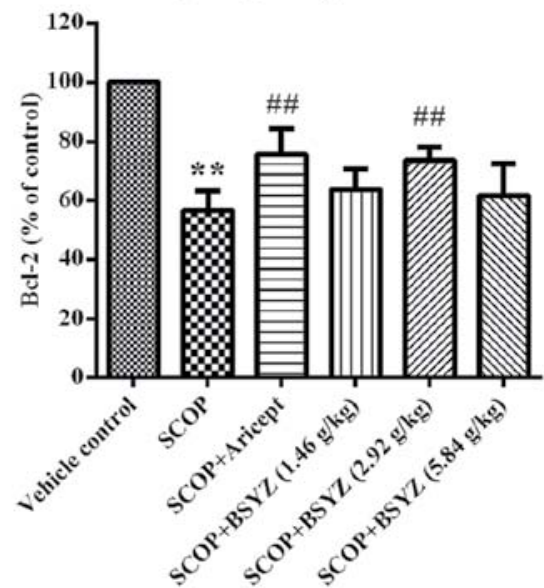

Figure 5. Immunofluorescent staining of Bax and Bcl-2 in the hippocampus of mice. (A) The expression of Bax and Bcl-2 in the hippocampus of SCOP-treated mice analyzed by immunofluorescent staining (scale bar, $100 \mu \mathrm{m}$; original magnification, x400). Bax was labeled with FITC (green) and Bcl-2 was labeled with Cy3 (red). a, Vehicle control; b, SCOP; c, SCOP + Aricept; d, SCOP + Bushen-Yizhi formula (BSYZ) (1.46 g/kg); e, SCOP + BSYZ (2.92 g/kg); $\mathrm{f}, \mathrm{SCOP}+\mathrm{BSYZ}(5.84 \mathrm{~g} / \mathrm{kg}$ ). (B) Percentage in mean fluorescence intensity (MFI) of Bax to the vehicle control mice. (C) Percentage in MFI of Bcl-2 compared to the control mice. Data are shown as the mean $\pm \mathrm{SE}(\mathrm{n}=3) .{ }^{* *} \mathrm{P}<0.01$ versus the vehicle control mice. ${ }^{\#} \mathrm{P}<0.05$ and ${ }^{\# \#} \mathrm{P}<0.01$ versus the $\mathrm{SCOP}$-treated mice.

Numerous genes are involved in the regulation of the mitochondrial apoptotic pathway. The proto-oncogene Bcl-2 is an inhibitor of apoptosis protein which exerts anti-apoptotic effects. In our study, SCOP significantly reduced the expres- 

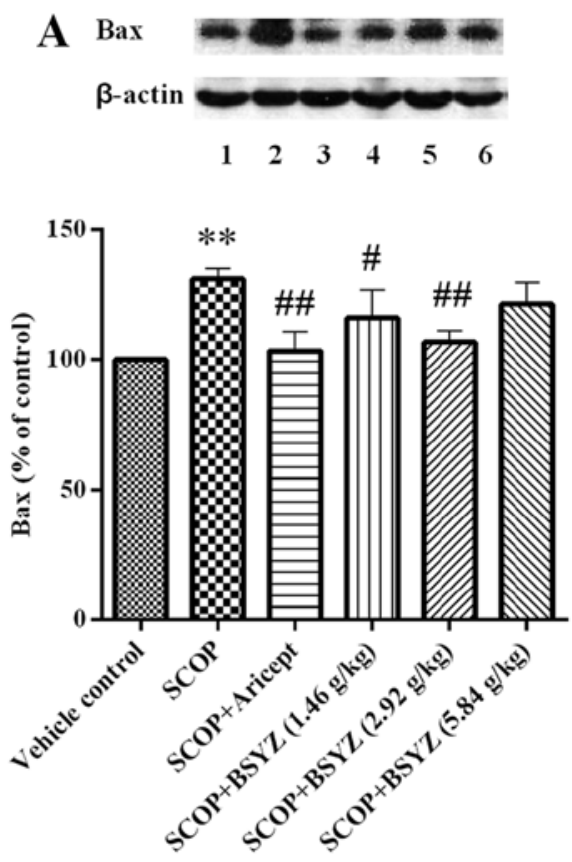
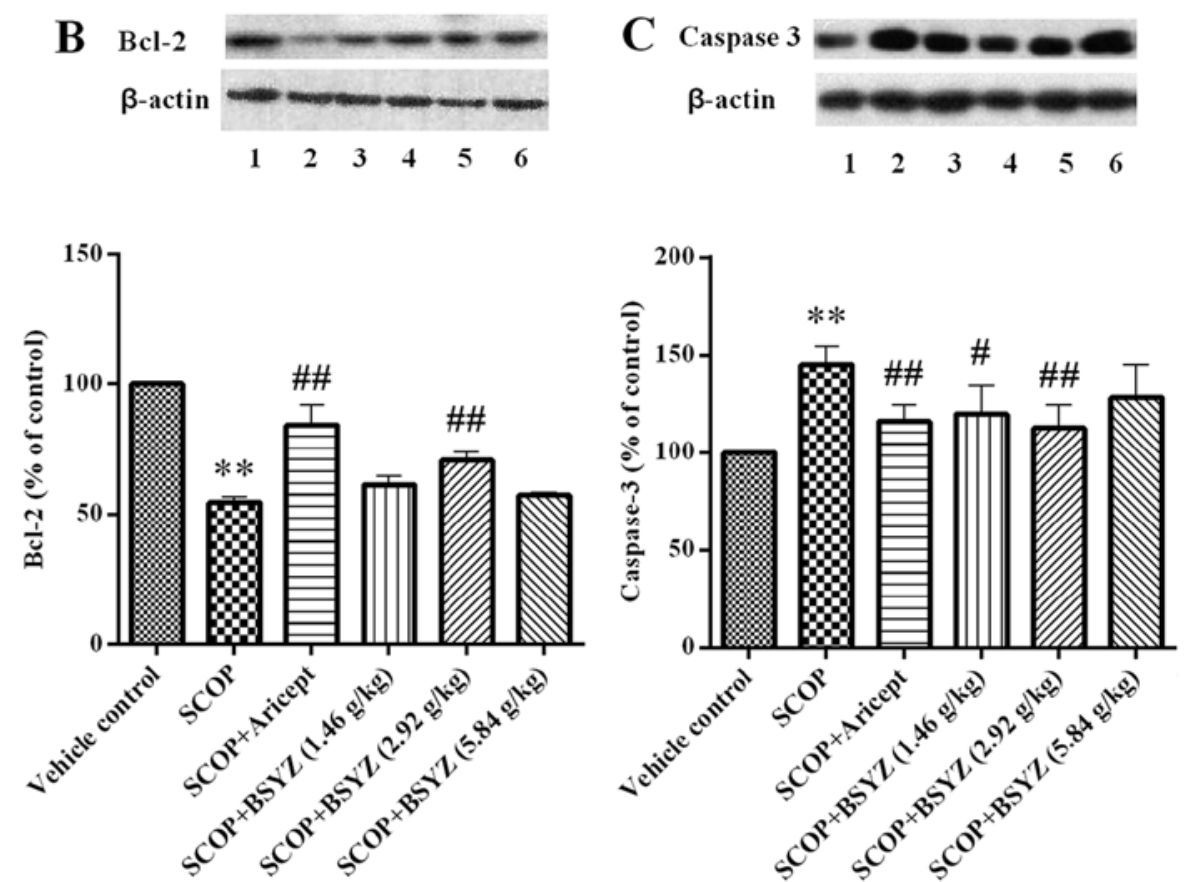

Figure 6. Effect of Bushen-Yizhi formula (BSYZ) on the expression of Bax, Bcl-2 and caspase-3 proteins. A, B and C show the expression of Bax, Bcl-2 and caspase-3 proteins, respectively; lanes 1, Vehicle control; 2, SCOP; 3, SCOP + Aricept; 4, SCOP + BSYZ (1.46 g/kg); 5, SCOP + BSYZ (2.92 g/kg); 6, SCOP + BSYZ $(5.84 \mathrm{~g} / \mathrm{kg})$; Data are shown as the mean $\pm \mathrm{SE}(\mathrm{n}=3) .{ }^{* *} \mathrm{P}<0.01$ versus the vehicle control mice. ${ }^{\#} \mathrm{P}<0.05$ and ${ }^{\# \#} \mathrm{P}<0.01 \mathrm{versus}$ the $\mathrm{SCOP}$-treated mice.

sion of Bcl-2 protein in the hippocampus of mice, while BSYZ and Aricept both induced an upregulation.

Bax, a pro-apoptotic protein, exerts an opposite effect to $\mathrm{Bcl}-2$. It was reported that a high expression of Bax protein promoted cell death. The ratio of Bcl-2 to Bax determines the susceptibility of cell apoptosis. Caspase-3, a key executioner of apoptosis in programmed cell death, was able to induce neuronal dysfunction (32). Studies have shown that an increase of Bcl-2 and a decrease of Bax prevented the release of cytochrome $c$ in mitochondria, and therefore inhibit the cascade of apoptosis. Our results demonstrate that BSYZ arrested the upregulation of Bax in the hippocampus of SCOP-treated mice, which enhanced the modulation of apoptosis. Moreover, the results show that BSYZ reversed the elevation of caspase-3 activity in the hippocampus of SCOP-treated mice by western blot analysis.

Recently, multi-targeted therapy is employed in various diseases, particularly those associated with different pathogenesis. In traditional Chinese medicine, plant extracts from different herbs in a formula may contain different ingredients, which may play a different role in treating the same disease. Furthermore, it was reported that different ingredients potentiated each other's effect (33). It was identified by HPLC that BSYZ consisted of eight major components, including Ginsenoside Rb1, Ginsenoside Rg1, Osthole, Imperatorin, Paeoniflorin,Paeonolum, Oleanic acid and 2,3,5,4'-tetrahydroxystilbene-2-O- $\beta$-D-glucoside, from its six herbs respectively. The pharmacological effects of the components were various, such as antioxidant, neuroprotective effect, anti-apoptotic and anti-inflammatory (34-37). Moreover, it has been reported that some of the components had beneficial effects in the improvement of learning and memory ability $(38,39)$.
Findings of our study suggest that BSYZ exerted a neuroprotective effect in SCOP-treated mice. The mechanism involved was presumably the regulation of oxidative stress and the expression of mitochondrial-mediated apoptosis-related proteins. However, it is essential to perform a further study to elucidate the detailed mechanism.

In summary, SCOP induced learning and memory impairment of mice. Moreover, BSYZ effectively improved cognitive ability and restored the abnormal activity of SOD and levels of MDA and GSH, reversed neural apoptosis, downregulated the expression of Bax and caspase- 3 and upregulated the expression of Bcl-2 in the hippocampus. These data suggest that BSYZ exerted enhancing cognitive function, which may result from the regulation of the antioxidative defense system and mitochondrial-mediated apoptosis mechanism. BSYZ is therefore a potential therapeutic agent for AD. However, future investigations should be conducted to demonstrate the effects of BSYZ on AD.

\section{Acknowledgements}

This study was supported by the National Natural Science Foundation of China(no.81273817),DoctoralFund of Education Ministry of China (no. 20114425110007 and 20124425120016), Guangdong Provincial Major Science and Technology for Special Program of China (no. 2012A080202017), the Guangdong Provincial Department of Science and Technology Foundation of China (no. 2010A030100009), Guangdong Provincial Natural Science Foundation of China (no. S2012040006514), the Scientific and Technical Innovation Project of Guangdong Provincial Education Department of China (no. 2012KJCX0032), the Characteristic 
Key Discipline Construction Fund of Chinese Internal Medicine of Guangzhou University of Chinese Medicine.

\section{References}

1. Pepeu G and Marconcini Pepeu I: Dysfunction of the brain cholinergic system during aging and after lesions of the nucleus basalis of Meynert. J Neural Transm Suppl 44: 189-194, 1994.

2. Schliebs R, Rossner S and Bigl V: Immunolesion by 192IgG-saporin of rat basal forebrain cholinergic system: a useful tool to produce cortical cholinergic dysfunction. Prog Brain Res 109: 253-264, 1996.

3. Niewiadomska G, Baksalerska-Pazera M and Riedel G: The septo-hippocampal system, learning and recovery of function. Prog Neuropsychopharmacol Biol Psychiatry 33: 791-805, 2009.

4. Saykin AJ, Wishart HA, Rabin LA, Flashman LA, McHugh TL, Mamourian AC and Santulli RB: Cholinergic enhancement of frontal lobe activity in mild cognitive impairment. Brain 127 1574-1583, 2004.

5. Geldmacher DS: Donepezil (Aricept) for treatment of Alzheimer's disease and other dementing conditions. Expert Rev Neurother 4 $5-16,2004$

6. Gupta R and Gupta LK: Improvement in long term and visuo-spatial memory following chronic pioglitazone in mouse model of Alzheimer's disease. Pharmacol Biochem Behav 102: 184-190, 2012

7. Richetti SK, Blank M, Capiotti KM, Piato AL, Bogo MR, Vianna MR and Bonan CD: Quercetin and rutin prevent scopolamine-induced memory impairment in zebrafish. Behav Brain Res 217: 10-15, 2011.

8. Knox LT, Jing Y, Fleete MS, Collie ND, Zhang H and Liu P: Scopolamine impairs behavioural function and arginine metabolism in the rat dentate gyrus. Neuropharmacology 61 : $1452-1462,2011$

9. Kwon SH, Lee HK, Kim JA, Hong SI, Kim HC, Jo TH, Park YI, Lee CK, Kim YB, Lee SY and Jang CG: Neuroprotective effects of chlorogenic acid on scopolamine-induced amnesia via anti-acetylcholinesterase and anti-oxidative activities in mice. Eur J Pharmacol 649: 210-217, 2010.

10. Praticò D: Evidence of oxidative stress in Alzheimer's disease brain and antioxidant therapy: lights and shadows. Ann NY Acad Sci 1147: 70-78, 2008.

11. Choi J, Conrad CC, Malakowsky CA, Talent JM, Yuan CS and Gracy RW: Flavones from Scutellaria baicalensis Georgi attenuate apoptosis and protein oxidation in neuronal cell lines. Biochim Biophys Acta 1571: 201-210, 2002.

12. Zhang H, Liu Y, Lao M, Ma Z and Yi X: Puerarin protects Alzheimer's disease neuronal cybrids from oxidant-stress induced apoptosis by inhibiting pro-death signaling pathways. Exp Gerontol 46: 30-37, 2011.

13. Capurro V, Busquet P, Lopes JP, Bertorelli R, Tarozzo G, Bolognesi ML, Piomelli D, Reggiani A and Cavalli A: Pharmacological characterization of memoquin, a multi-target compound for the treatment of Alzheimer's disease. PLoS One 8 : e56870, 2013.

14. Li H, Li SL, Gong L, Wang JL, Li YZ and Wu ZH: The effects of an herbal medicine $\mathrm{Bu}-W a n g-S a n$ on learning and memory of ovariectomized female rat. J Ethnopharmacology 117 : 427-432, 2008

15. Zhang GR, Cheng XR, Zhou WX and Zhang YX: Age-related expression of calcium/calmodulin-dependent protein kinase II A in the hippocampus and cerebral cortex of senescence accelerated mouse prone $/ 8$ mice is modulated by anti-Alzheimer's disease drugs. Neuroscience 159: 308-315, 2009.

16. Lan Z, Liu J, Chen L, Fu Q, Luo J, Qu R, Kong L and Ma S: Danggui-Shaoyao-San ameliorates cognition deficits and attenuates oxidative stress-related neuronal apoptosis in d-galactose-induced senescent mice. J Ethnopharmacol 141: 386-395, 2012

17. Li L, Wei HF, Zhang L, Chu J and Zhao L: Modern biological basis of Chinese medical theory that 'kidney nourishes marrow and brain is sea of marrow'. Zhongguo Zhong Yao Za Zhi 31: 1397-1400, 2006 (In Chinese).

18. Howes MJ and Houghton PJ: Plants used in Chinese and Indian traditional medicine for improvement of memory and cognitive function. Pharmacol Biochem Behav 75: 513-527, 2003.
19. Lin HQ, Ho MT, Lau LS, Wong KK, Shaw P and Wan DC: Anti-acetylcholinesterase activities of traditional Chinese medicine for treating Alzheimer's disease. Chem Biol Interact 175: 352-354, 2008

20. Zhong ZG, Liu MC and Lai SL: Effect of bushen yizhi formula on neurotransmitter release in rat models with Alzheimer disease Chin J Clin Rehabil 44: 167-170, 2005.

21. Chen YB, Lai SL, Hu JQ, Wang Q and Cheng SY: Effects of drug serum in broken bushen yizhi formulas on cell model of Alzheimer disease. Chin J Clin Rehabil 32: 250-253, 2005.

22. Morris R: Developments of a water-maze procedure for studying spatial learning in the rat. J Neurosci Methods 11: 47-60, 1984.

23. Himeno E, Ohyagi Y, Ma L, Nakamura N, Miyoshi K, Sakae N, Motomura K, Soejima N, Yamasaki R, Hashimoto T, Tabira T, LaFerla FM and Kira J: Apomorphine treatment in Alzheimer mice promoting amyloid- $\beta$ degradation. Ann Neurol 69: 248-256, 2011.

24. Molchan SE, Mellow AM, Hill JL, Weingartner H, Martinez R, Vitiello B and Sunderland T: The effects of thyrotropin-releasing hormone and scopolamine in Alzheimer's disease and normal volunteers. J Psychopharmacol 6: 489-500, 1992.

25. Shi J, Liu Q, Wang Y and Luo G: Coadministration of huperzine A and ligustrazine phosphate effectively reverses scopolamineinduced amnesia in rats. Pharmacol Biochem Behav 96: 449-453, 2010.

26. Jahanshahi M, Nickmahzar EG and Babakordi F: Effect of Gingko biloba extract on scopolamine-induced apoptosis in the hippocampus of rats. Anat Sci Int 88: 217-222, 2013.

27. Kim DH, Jeon SJ, Son KH, Jung JW, Lee S, Yoon BH, Lee JJ, Cho YW, Cheong JH, Ko KH and Ryu JH: The ameliorating effect of oroxylin A on scopolamine-induced memory impairment in mice. Neurobiol Learn Mem 87: 536-546, 2007.

28. Lazareno S, Popham A and Birdsall NJ: Towards a high-affinity allosteric enhancer at muscarinic M1 receptors. J Mol Neurosci 19: 123-127, 2002.

29. Higgins GA, Enderlin M, Fimbel R, Haman M, Grottick AJ, Soriano M, Richards JG, Kemp JA and Gill R: Donepezil reverses a mnemonic deficit produced by scopolamine but not by perforant path lesion or transient cerebral ischaemia. Eur J Neurosci 15: 1827-1840, 2002.

30. Birks J and Harvey RJ: Donepezil for dementia due to Alzheimer"s disease (Review). Cochrane Database of Systematic Reviews: 1, 2006.

31. Takada Y,Yonezawa A,Kume T,KatsukiH,KanekoS,SugimotoH and Akaike A: Nicotinic acetylcholine receptor-mediated neuroprotection by donepezil against glutamate neurotoxicity in rat cortical neurons. J Pharmacol Exp Ther 306: 772-777, 2003.

32. Qian YF, Wang H, Yao WB and Gao XD: Aqueous extract of the Chinese medicine, Danggui-Shaoyao-San, inhibits apoptosis in hydrogen peroxide-induced PC12 cells by preventing cytochrome c release and inactivating of caspase cascade. Cell Biol Int 32: 304-311, 2008.

33. Yi LT, Xu Q, Li YC, Yang L and Kong LD: Antidepressant-like synergism of extracts from magnolia bark and ginger rhizome alone and in combination in mice. Prog Neuropsychopharmacol Biol Psychiatry 33: 616-624, 2009.

34. Liu Q, Kou JP and Yu BY: Ginsenoside Rg1 protects against hydrogen peroxide-induced cell death in $\mathrm{PC} 12$ cells via inhibiting NF- $\kappa$ B activation. Neurochem Int 58: 119-125, 2011.

35. Qian YH, Han H, Hu XD and Shi LL: Protective effect of ginsenoside $\mathrm{Rb} 1$ on beta-amyloid protein(1-42)-induced neurotoxicity in cortical neurons. Neurol Res 31: 663-667, 2009.

36. Cheng Y, Shen LH and Zhang JT: Anti-amnestic and anti-aging effects of ginsenoside Rg1 and Rb1 and its mechanism of action. Acta Pharmacol Sin 26: 143-149, 2005.

37. Sun R, Wang K, Wu D, Li X and Ou Y: Protective effect of paeoniflorin against glutamate-induced neurotoxicity in PC12 cells via $\mathrm{Bcl}-2 / \mathrm{Bax}$ signal pathway. Folia Neuropathol 50: 270-276, 2012.

38. Zhang X, Wang J, Xing Y, Gong L, Li H, Wu Z, Li Y, Wang J, Wang Y, Dong L and Li S: Effects of ginsenoside Rg1 or $17 \beta$-estradiol on a cognitively impaired, ovariectomized rat model of Alzheimer's disease. Neuroscience 220: 191-200, 2012.

39. Zhou L, Hou Y, Yang Q, Du X, Li M, Yuan M and Zhou Z: Tetrahydroxystilbene glucoside improves the learning and memory of amyloid- $\beta\left({ }_{1-42}\right)$-injected rats and may be connected to synaptic changes in the hippocampus. Can J Physiol Pharmacol 90: 1446-1455, 2012. 